University of Maryland Francis King Carey School of Law

DigitalCommons@UM Carey Law

3-1-2003

\title{
Achieving the Right Balance in Oversight of Physician Opioid Prescribing for Pain: The Role of State Medical Boards
}

Diane E. Hoffmann

University of Maryland School of Law, dhoffmann@law.umaryland.edu

Anita J. Tarzian

Follow this and additional works at: https://digitalcommons.law.umaryland.edu/fac_pubs

Part of the Bioethics and Medical Ethics Commons, and the Health Law and Policy Commons

\section{Digital Commons Citation}

Hoffmann, Diane E. and Tarzian, Anita J., "Achieving the Right Balance in Oversight of Physician Opioid Prescribing for Pain: The Role of State Medical Boards" (2003). Faculty Scholarship. 146.

https://digitalcommons.law.umaryland.edu/fac_pubs/146

This Article is brought to you for free and open access by the Francis King Carey School of Law Faculty at DigitalCommons@UM Carey Law. It has been accepted for inclusion in Faculty Scholarship by an authorized administrator of DigitalCommons@UM Carey Law. For more information, please contact smccarty@law.umaryland.edu. 


\title{
Achieving the Right Balance in Oversight of Physician Opioid Prescribing for Pain: The Role of State Medical Boards
}

\author{
Diane E. Hoffmann and Anita J. Tarzian
}

$\mathrm{U}$ ncertainty regarding potential disciplinary action may give physicians pause when considering whether to accept a chronic pain patient or how to treat a patient who may require long-term or high doses of opioids. Surveys have shown that physicians fear potential disciplinary action for prescribing controlled substances and that physicians will, in some cases, inadequately prescribe opioids due to fear of regulatory scrutiny. Prescribing opioids for long-term pain management, particularly noncancer pain management, has been controversial; and boards have investigated and, in some cases, disciplined physicians for such prescribing. While in virtually all of these cases the disciplinary actions were successfully appealed, news of the success was not often as well-publicized as news of the disciplinary actions, leaving some physicians confused about their potential liability when prescribing opioids for pain. The confusion has perhaps increased as a result of two relatively recent cases, one where a physician was successfully disciplined by a state medical board for undertreatment of his patients' pain, and another where the physician was successfully sued for inadequate pain treatment.

In the first case, in September 1999, the Oregon Medical Board disciplined a physician for failure to adequately treat several of his patients for pain. Less than two years later, a California physician was successfully sued for his undertreatment of a patient's pain. These cases reflect a changing attitude toward pain treatment in the United States - a recognition that patients, especially patients at the end of life, have a right to adequate pain treatment. This shift in thinking appears to have begun in the late $1980 \mathrm{~s}$. Prior to this time, "according to established medical opinion, the likelihood of addiction to opioids was considered too great

Journal of Law, Medicine ê Ethics, 31 (2003): 21-40.

(C) 2003 by the American Society of Law, Medicine \& Ethics. to prescribe them to any patients but those suffering from the most serious pain." This opinion was conveyed by a number of state medical boards to physicians who were disciplined for prescribing outside of these boundaries. The "sea change" came about "as evidence mounted that patients, especially cancer patients, were being undertreated for their pain, and that addiction was not a significant problem for pain patients with no prior history of substance abuse." In response, physicians began to prescribe greater amounts of pain medication. In addition, professional and governmental agencies established clinical guidelines encouraging the appropriate use of opioids in the treatment of cancer pain. Many state legislatures also passed "intractable pain statutes." These laws "were designed to provide physicians with some assurances by reducing both the real and perceived risks of being subjected to regulatory sanctions for treating pain with controlled substances." ${ }^{3}$

Yet, at the same time that these new legal pressures would seem to counteract the pressures to undertreat, a renewed concern about drug diversion, in light of the abuse associated with OxyContin, has taken shape. Evidence of diversion of the medication from legitimate users to addicts has caught the attention of drug and law enforcement agencies that have linked OxyContin to overdose deaths, pharmacy robberies, and other criminal activities related to obtaining the drug. This turn of events has the potential for rekindling the attention of state medical boards and law enforcement agencies toward physician prescribing practices for patients suffering from pain.

In an effort to better understand how state medical boards are evaluating and balancing the need for adequate pain treatment with concerns about drug diversion and inappropriate prescribing, we undertook a survey of state medical boards across the country. This article, after briefly describing the evolution of medical knowledge regarding the treatment of 
pain, the history of efforts to regulate controlled substances used to treat pain, and the literature regarding physician concerns about legal repercussions for prescribing opioids, reports on the results of the survey.

We conclude that boards have made improvements in the way they approach physicians who prescribe large doses of opioids. Greater reliance on pain policies has given many boards clearer criteria for when to investigate and discipline physicians for opioid prescribing violations. The observed improvements involve recognition by most boards that physicians have an obligation to provide adequate pain management to their patients. This recognition has required boards to balance their concerns about opioid overprescribing with their concerns about pain undertreatment. We found, however, that boards appear to be more concerned with violation of standard of care in cases of overtreatment versus undertreatment. Respondents (speaking on behalf of their boards) viewed opioid overprescribing as a clear violation of standard of care and a clear example of patient harm, whereas pain undertreatment - particularly for nonmalignant chronic pain - was not so clearly perceived as a standard of care violation, and generally required a higher threshold of harm. We conclude that the boards are still trying to find the right balance between promoting adequate pain management and protecting against opioid diversion and abuse.

\section{The Evolution of Treating Pain with Opioids}

Progress in pain management has evolved over the last few decades. Beginning with the hospice movement in the $1960 \mathrm{~s}$, and continuing beyond the 1994 guidelines for the management of cancer pain published by the Agency for Health Care Policy \& Research, opioids (in combination with other medications) have been identified as the standard treatment for moderate to severe cancer pain. In addition, opioid therapy has been shown to be effective for patients with certain types of chronic nonmalignant pain, without the occurrence of intolerable side-effects or the development of aberrant drug-related behaviors. ${ }^{4}$ Its use in patients with malignant and nonmalignant pain has been shown to improve functional status and quality of life. ${ }^{5}$ Moreover, the consensus among addiction specialists is that substance abuse history per se does not preclude the use of opioids for pain management, but it does mandate careful assessment and monitoring of such patients by a trained pain specialist. ${ }^{6}$

At the same time that these pain management treatment standards have evolved, there have been ongoing efforts to regulate the prescribing of opioids. These efforts began with the passage in 1970 of the Controlled Substances Act and the establishment in 1973 of the Drug Enforcement Agency (DEA). At the federal level, the Controlled Substances Act and the DEA make up the main armaments in the government's efforts to prevent drug abuse. At the state level, there are comparable laws as well as state drug enforcement agencies and bureaus of narcotics control. Since the 1970 s, the government's attitude has shifted in focus, particularly after President Reagan took office, from viewing drug abuse as a public health problem to viewing it as a political, law enforcement, and moral issue. ${ }^{7}$ Although the DEA and other federal laws and policies tend to be less restrictive of physician practices than state laws and enforcement practices, concerns about Medicare and Medicaid fraud and abuse and the government's "war on drugs" have put pressure on state medical boards. ${ }^{8}$ This has resulted in some state boards disciplining physicians for "overprescribing" opioids, including physicians who were treating pain patients. ${ }^{9}$ Thus, in addition to fears that patients will become addicted, ${ }^{10}$ and that doses of opioids that are too high will lead to patient deaths, ${ }^{11}$ physicians avoid prescribing opioids because they believe they may face legal or regulatory sanctions or simply be the target of investigation by licensing boards or other law enforcement agencies. ${ }^{12}$ However, research has shown that physicians' fears of legal or regulatory sanctions are more the result of a "chilling effect" than of the actual risk of disciplinary or legal liability they face if they properly prescribe opioids for pain management. ${ }^{13}$

Several physician surveys have provided evidence of the chilling effect of sanctions against physicians for opioid prescribing. In 1990, physician members of the Eastern Cooperative Oncology Group were surveyed and 18 percent of 897 responding oncologists rated excessive regulation of analgesics as one of the top four barriers to adequate cancer pain management. ${ }^{14}$ In a 1991 survey of members of the American Pain Society, 40 percent of surveyed physician members said concerns about regulatory scrutiny rather than medical reasons led them to avoid prescribing opioids for chronic noncancer pain patients. ${ }^{15}$ In a survey of Wisconsin physicians conducted in the same year, over half reported decreasing the dose, quantity, or number of refills, or switching to a lower scheduled medication, due to fear of regulatory scrutiny. ${ }^{16}$ And, in a 1993 California survey, 69 percent of physician respondents felt that doctors were more conservative in their use of opioids in pain management because of fear of disciplinary action, and a third felt that their own patients may be suffering from untreated pain. ${ }^{17}$

In an effort to better understand state medical board members' knowledge and attitudes toward physician prescribing of opioids for pain management, the University of Wisconsin Pain \& Policy Studies Group (PPSG) conducted a survey of members of state medical boards in 1991. Joranson and colleagues found that " $[w]$ hile most respondents agreed that the prescribing of opioids for the cancer patient was legal and generally acceptable medical practice, only $12 \%$ were confident in the legality of prescribing for the patient with chronic non-cancer pain; the majority of respondents $(77 \%)$ would discourage this practice or even investigate it as a violation of the law." 18 They also found that board members responding to the survey had a lack of knowledge about 
cancer pain management and the meaning and incidence of addiction when opioids are used to manage pain. In 1997, the PPSG (which conducted workshops between 1994 and 1998 to educate board members around the country about pain management issues) repeated the survey and found some improvements in attitudes of medical board members. Specifically:

- respondents were more likely in 1997 than in 1991 to recognize that opioids are underutilized as analgesics for cancer pain;

- respondents in both surveys overestimated the incidence of addiction to pain medications, but in 1997 fewer respondents confused addiction with physical dependence; and

- medical board members in 1991 and 1997 were more skeptical about prescribing opioids for noncancer than for cancer pain, but respondents in 1997 were more likely to consider prescribing opioids to patients with chronic noncancer pain for more than several months as acceptable medical practice. ${ }^{19}$

Since 1997 there have been a number of changes in the legal landscape regarding the prescribing of opioids for pain. Recently there has been an increased focus on undertreatment of pain, influenced in part by the increased attention given to palliative and end-of-life care and the controversy surrounding physician-assisted suicide. The American Society of Law, Medicine \& Ethics (ASLME), with support from the Mayday Fund,,$^{20}$ has addressed the issue of pain undertreatment through a variety of educational initiatives and projects. In 1998, ASLME's joint work with the Federation of State Medical Boards (FSMB) resulted in 1998 in the Model Guidelines for the Use of Controlled Substances for the Treatment of Pain, thus giving clear guidance to state medical boards regarding opioid use for chronic pain. ${ }^{21}$ The PPSG has been tracking the adoption of the Model Guidelines as well as other state pain policies more generally for over a decade. From 1989 to 2001, there was a dramatic increase in the number of new state pain policies adopted by state boards and legislatures. Many state boards have adopted policies that are consistent with the FSMB's Model Guidelines (e.g., endorsement of a balance between preventing opioid misuse and not interfering with appropriate opioid prescribing; endorsement of multidisciplinary collaboration in treating pain patients; inclusion of treatment standards for chronic nonmalignant pain as well as standards for acute and cancer-related pain). ${ }^{22}$ However, there is no literature indicating how state boards are applying the guidelines and whether they are implementing balanced policies for the management of both malignant and nonmalignant pain.

In addition to the efforts of the ASLME, PPSG, and FSMB, groups like Compassion in Dying have been trying to counter the chilling effect of sanctions for opioid prescribing by drawing attention to cases in which pain was undertreated.
In 1999, the Oregon Medical Board was the first in the nation to discipline a physician for failure to prescribe adequate pain relief medication. The physician, Dr. Paul Bilder, was cited for several pain undertreatment infractions, including prescribing insufficient pain medication for a terminally ill cancer patient (i.e., only Tylenol) and prescribing only a fraction of the dose of morphine that another patient needed and the hospice nurse suggested. Dr. Bilder was ordered by the medical board to complete an educational program on physician-patient communication and undergo mental health treatment. ${ }^{23}$ In another case, in June 2001, a California jury awarded 1.5 million dollars to the surviving children of William Bergman, whose children sued their father's physician, Dr. Wing Chin, for undertreating Mr. Bergman's cancer pain before he died. Although the award was subsequently reduced by the court, it was a dramatic message to physicians. Moreover, in the same year, drug enforcement officials from the DEA and twenty-one health organizations issued a joint statement that they had begun to work together "to prevent abuse of prescription pain medications while ensuring that they remain available for patients in need." ${ }^{24}$

Almost at the same time that we experienced this shift in focus toward concerns about undertreatment of pain, a new risk surfaced that threatens the balance of providing effective pain relief while minimizing abuse and diversion of opioids - the abuse of OxyContin. OxyContin was approved by the Food and Drug Administration in 1995. It has fewer side-effects than morphine but works similarly. It contains oxycodone in a time-released formulation that works over 12 hours, making it ideal for sufferers of both malignant and nonmalignant chronic pain. However, abuse of the drug began when it was discovered that crushing the tablet and either snorting it or mixing it with water and injecting it produced a potent high. Thus, OxyContin has high addictive potential for drug abusers and a high street value. According to the DEA Office of Diversion Control, from 1996 to 1999 the number of drug abuse deaths reported to the Drug Abuse Warning Network (DAWN) that involved oxycodone more than quadrupled, with 268 deaths in 1999 compared to 51 in $1996 .{ }^{25}$ Several cases were reported in the media stating that physicians who prescribed OxyContin in relatively high doses were disciplined by their state medical boards. ${ }^{26}$

\section{Survey of State Medical Boards}

In order to better understand how state medical boards are balancing concerns about physicians undertreating pain with concerns about physicians overprescribing opioids, we undertook a nationwide survey of state medical boards. More specifically, the study sought information regarding trends in the number and nature of complaints received by boards for inappropriate prescribing of opioids (i.e., "overprescribing" or "underprescribing"), how boards evaluate such complaints, and under what circumstances boards would discipline phy- 
sicians falling into one of those categories. The focus of the survey was board experience during the last 5 years (19972001). The survey was conducted in late 2001 and the first half of 2002, just after the high visibility given to the abuse of OxyContin in the press.

\section{METHODS}

As a first step, we developed a telephone survey tool based on available literature and input from experts in the field of pain research and state medical board staff to identify state medical board practices related to prescribing of opioids for the treatment of pain. ${ }^{27}$ Survey questions included the nature of complaints the board received over the previous 5 years regarding opioid overprescribing and subsequent investigations of physicians and disciplinary action taken; the nature of complaints the board received regarding undertreatment of pain by a physician; the board's use of a pain management expert in cases involving opioid prescribing; the likelihood of the board taking disciplinary action against a physician for undertreatment of pain; and the board's educational activities directed to physicians regarding treatment of patients with pain. The study was approved by a University of Maryland institutional review board.

The survey was directed (by name) to the state board medical director, or individual with a comparable title, and that individual was asked to participate in the survey or to provide the name of someone else in the agency who would be most able to answer the survey questions. Of the fifty states and the District of Columbia, thirty-eight state medical boards participated (a 74.5 percent response rate). Seventeen respondents were state medical board directors, ten were chief investigators or prosecutors, and the remaining eleven included individuals with the following titles: "medical director," "medical consultant," "program administrator," "senior complaint analyst," "chief [or 'director'] of compliance," "consumer assistant," and "director of complaints and allegations." The respondents' average number of years in their current position was 6.0 (standard deviation $=5.7$ ). Ten respondents were physicians, seven were lawyers, three were nurses, two were social workers, and several had other advanced degrees (e.g., in business, public administration, and public health). Ten had worked in a similar capacity before working in their current position. Thirtyfour respondents completed the survey by phone, and four completed the survey in written form. ${ }^{28}$ Qualitative comments were transcribed directly from phone conversations or from written comments on faxed or mailed-in surveys.

Boards of those who responded differed in two significant respects from those who did not. First, respondents were more likely not to have regulations, guidelines, statutes, or policies regarding opioid prescribing than nonrespondents. Interestingly, all of the boards without such regulations, guidelines, statutes, or policies participated..$^{29}$ Second, respondents were more likely than nonrespondents to have implemented an electronic prescription monitoring program that provides access to a database of physicians' prescribing and pharmacists' dispensing practices from pharmacies in the state. A total of sixteen states have currently implemented a prescription monitoring program, all of which are electronic. ${ }^{30}$ Thirteen of those sixteen states responded to the survey.

\section{RESULTS}

\section{Opioid overprescribing: Complaints}

Respondents were asked to estimate the number of complaints ${ }^{31}$ their board had received in 2001 related to opioid overprescribing (i.e., "physicians who allegedly prescribed opioids unnecessarily, in too high a dose, or for too long a duration"). ${ }^{32}$ An estimate was requested because most boards do not formally categorize complaints that relate specifically to opioid overprescribing. ${ }^{33}$

Twenty-five respondents were able to estimate the number of opioid overprescribing complaints in 2001. According to those estimates, the average number of complaints was 3.1 per 1,000 doctors in the state (standard deviation $=2.8$, range $=0$ to 13.8$).{ }^{34}$ The most common sources of these complaints were pharmacies, government regulatory agencies such as the DEA, and family members of patients. Other sources included physicians, law enforcement agents, or the board itself (i.e., in the course of another investigation, the board may have discovered cases of suspected opioid overprescribing). Some qualifying comments regarding the number of complaints included: "some [complaints] run together, for example, a complaint about sexual involvement may overlap with [a complaint about] opioid overprescribing," and "we do not track it that way, but my sense is, it's extremely small. Out of 700 complaints ... under a dozen tend to be related to [opioid overprescribing, mostly criminal referral]."

Eleven respondents were not able to estimate the number of opioid overprescribing complaints their board received in 2001 and shared comments such as: "we don't keep that type of information.... [W] categorize drug diversion, incompetence, negligence.... I really don't know"; "I know the number of complaints for inappropriate prescribing, but I don't know how many of those were for opioid overprescribing"; and "I couldn't give a fair estimate, we have codes within our tracking system, but a lot of time the tracking code we put in isn't the same as the order to show cause or the final adjudication." In this regard, one respondent reported that his board was "getting ready to add undertreatment of pain to the [complaint form] as a specific cause."

When respondents were asked their impression of whether complaints against physicians for opioid overprescribing had increased, decreased, or stayed the same in the 


\begin{tabular}{|c|c|c|c|c|}
\hline & INCREASED & DECREASED & StAYED THE SAME & No OpINION \\
\hline Complaints & $\begin{array}{c}14 \\
(37 \%)\end{array}$ & $\begin{array}{c}4 \\
(10.5 \%)\end{array}$ & $\begin{array}{c}17 \\
(44.5 \%)\end{array}$ & $\begin{array}{c}3 \\
(8 \%)\end{array}$ \\
\hline Investigations & $\begin{array}{c}15 \\
(39.5 \%)\end{array}$ & $\begin{array}{c}3 \\
(8 \%)\end{array}$ & $\begin{array}{c}17 \\
(44.5 \%)\end{array}$ & $\begin{array}{c}3 \\
(8 \%)\end{array}$ \\
\hline Disciplinary Actions & $\begin{array}{c}14 \\
(37 \%)\end{array}$ & $\begin{array}{c}6 \\
(16 \%)\end{array}$ & $\begin{array}{c}15 \\
(39.5 \%)\end{array}$ & $\begin{array}{c}3 \\
(8 \%)\end{array}$ \\
\hline
\end{tabular}

past 5 years, seventeen respondents ( 44.5 percent) thought complaints had stayed the same ("on average there's a relatively fixed population of drug-seeking patients and a relatively constant population of providers willing to prescribe"), fourteen (37 percent) thought they had increased, four (10.5 percent) thought they had decreased, and three did not know (see Table 1).

\section{Drug diversion and abuse trends: OxyContin}

Respondents were asked whether the problem of drug diversion and abuse in their state, in general, had improved, become worse, or stayed the same in the last 5 years. Eighteen (47 percent) thought it had become worse, eleven ( 29 percent) thought it had stayed the same, and five (13 percent) thought it had improved. Four had no real impression. Some commented that the drug diversion/abuse problem was not necessarily worse, but the board was doing more ("taking a little sterner approach than before 1996"; "pursuing it more diligently; we're more on top of it now"; and "we have more sophisticated investigatory techniques, so we may just be more aware of what's going on"). Fifteen of the eighteen who thought drug diversion and abuse in their state had become worse ( 83 percent) thought that the abuse and diversion of OxyContin had contributed to that trend, while the remaining three thought it had not. Some identified the problems with OxyContin as prompting newly enacted legislation establishing a prescription monitoring program in the state. One respondent commented:

Any time you have a drug that has as much press as [OxyContin], it identifies weaknesses in systems. Then you have people who are more willing to look for new ways to identify diversion and abuse. This might be one aspect that plays into the desire of some to have this new drug monitoring system ... [to find] mechanisms to identify if a patient had been to other physicians [looking for drugs to feed an addiction], or indications of [drug] diversion/ abuse, for peace of mind of the physician.
Another stated: "an electronic database system would be ideal. It works both ways: If a doctor wonders if he's the sixth doc in the pathway, he can call the board and get the answer in a few minutes, and [vice versa]."

Some respondents thought the abuse of OxyContin had made the public more aware of diversion issues, but had "not increased [their] complaints or investigations." Others made reference to OxyContin's being "the drug of the month" ("20 years ago it was Dilaudid, then Percocet, once upon a time it was Demerol"; "OxyContin is a new problem, but Lortab is more abused; there's still a diverse array of drugs"; "OxyContin is just another drug in the mix"). One respondent commented: "we don't have issues with physicians abusing OxyContin.... [O]ur problem has been with patients selling or diverting the OxyContin and physicians not tuning in to that." A few respondents, however, described serious problems in their state with overdose deaths from OxyContin, or of people in their state breaking into pharmacies and holding pharmacists up at gunpoint, specifically requesting OxyContin ("we have seen a tremendous problem of criminal theft of OxyContin"). One respondent described local police and health care providers with an "otherwise unblemished record for 20 years ... getting addicted to OxyContin ... [and] stealing from patients." Others reported increased prescriptions of OxyContin, but as one respondent commented: "that's not proof of diversion."

\section{Investigations for overprescribing}

When asked whether their board had changed its approach to investigating physicians for opioid prescribing in response to OxyContin abuse and diversion, twenty-nine (76 percent) said no and five (13 percent) said yes. Four had no opinion. Those who had not changed their approach commented that they conducted the "same thorough investigation" of all valid complaints. Others felt their investigative approach had not changed, but their attention to the issue had increased. One respondent identified drug diversion as a priority of the board, which was working more with law enforcement to "stay on top of what's going on." Another respondent explained that 
the approach of their board included adapting to changes in drug-seeking and diversion behaviors over the years:

[The] physician's committee of the medical society ... offers very consistent counsel; they've tightened their procedures over the years because the screening tests we had in place for monitoring [opioids] needed to be beefed up. They found loopholes like ... "beat-the-piss-test.com" websites, [which led to requiring] all testing at one lab. We've gone back and identified a lot of problems. It's better to nip it in the bud before it gets too out of control.

\section{Another respondent commented:}

It's just a change in the marketplace we've taken cognizance of. We just had a huge case of overprescribing where in the testimony it became apparent the number of patients looking for this kind of prescriber. This particular doc had people coming from other states. That was his defense: "If someone is in pain, you give them drugs." But the board said, "Not necessarily. You comply with good medical practice; you assess them and follow up and keep records, etc. You don't just give them drugs."

Respondents from other boards admitted that finding the right balance between identifying physicians who overprescribe opioids and those who are appropriately treating chronic pain is not always easy. As one respondent stated: "[We're] still working on trying to figure out the appropriate balance between pain management and overprescribing. We're still looking at research to find that balance."

When asked whether board investigations of physicians' opioid prescribing practices had increased, decreased, or stayed the same over the past 5 years (1997-2001), seventeen respondents (44.5 percent) said the number of investigations had stayed the same, fifteen ( 39.5 percent) said they had increased, three ( 8 percent) said they had decreased, and three did not know (see Table 1). Respondents were asked why they thought the number of investigations had increased or decreased. For those that answered increased, the most commonly cited reasons were increased "public awareness.... patients and families are more aware," and "people are more inclined to speak up than they have been in the past." Some mentioned law enforcement actions ("there have been more cases where there have been convictions [of physicians] on drug trafficking and selling [opioid] prescriptions for money").

For those that answered decreased, one respondent cited economic factors that limited the resources the board could direct toward investigations. Changes in the board's attitude toward opioid prescribing was mentioned as a reason for increased and decreased investigations over the past 5 years. One respondent shared his impression that "the board is taking these cases more seriously than in the past ... [by] cracking down on doctors who are overprescribing, and wanting us to find information to back that up." Another mentioned that physicians have clearer grounds for being investigated if they do not understand the board's rules for the treatment of chronic pain and are practicing outside of their specialty area. Others pointed to their board's changed attitude toward the treatment of chronic pain and how this has resulted in fewer full investigations: "The board's attitude toward prescribing opioids has changed. If a doctor can provide documentation showing that [s] he's following pain management guidelines, the board doesn't pursue [it] further."

Respondents were asked what factors would determine whether their board would fully investigate a physician for overprescribing opioids. ${ }^{35} \mathrm{~A}$ "full investigation" was defined as going beyond initial factfinding (i.e., beyond merely sending a letter of inquiry to a physician or reviewing pharmacy records). For example, one respondent explained that whenever his board received a complaint against a physician related to opioid prescribing, the board conducted a preliminary investigation during which it typically requested a two-year profile from the state pharmacy board to look at the general prescribing practices of the physician. If they saw a pattern of inappropriate prescribing or had received "a series of complaints over the years that point[ed] to there being a problem," this would trigger a full investigation. Six respondents stated that their boards fully investigate all complaints related to opioid overprescribing.

State pain guidelines, statutes, regulations, or policies were mentioned as providing guidance for when to proceed with a full investigation of a physician for overprescribing. All but six of the boards responding to the survey currently have some form of guideline (sixteen), statute (fifteen), regulation (twelve), or policy (nine) related to pain management. ${ }^{36}$ For many boards, if a complaint was made against a physician who was found not to be in compliance with the board's pain rules/guidelines, this would trigger a full investigation of that physician. Comments included: "if we don't have good documentation, if it doesn't appear that the physician's following the board's guidelines with respect to prescribing for pain, then we'll investigate"; "for the most part we adhere to [our pain guidelines].... [we've made] a lot of progress ... teaching physicians how to do this appropriately. We set the minimum standard of care in any state, documentation, informed consent, proper referral, etc., so we look for that"; and "the general policy that was made known to physicians is that we leave prescribing and pain management control issues to their professional judgment, but if there is a complaint, they better have proper documentation, such as informed consent, history and physical, monitoring, etc."

Some respondents commented that the volume or amount of opioids prescribed by a physician might trigger an 
investigation - for example, if there were "large numbers of patients receiving large numbers of opioids from the same individual who was seeing patients from a large geographic region, that would trigger an investigation." Also, "if there were extremely large dosages [prescribed], that would make [the board] question if the patient could safely consume that much." However, if there was evidence that backed up the need for the amount of opioids prescribed, most boards would not investigate further (e.g., "if we determined that they were providing therapeutic interventions, then we would close the investigation"). One respondent provided the following example:

If a person [has] had low back pain for the last 12 years and has been taking long-term increasing doses of pain medicine over the years, and the family is reporting it because [their family member is] an addict now, that would be investigated. Any allegation that the pain is not sufficient to warrant the prescribed opioid [would be investigated], so if it's a cancer patient, no one will argue with that.

Another commented:

If we get a complaint that a doc's prescribing OxyContin $80 \mathrm{mg}$ four times a day or three times a day, ${ }^{37}$ we'll ask the pharmacist if it's a cancer patient. Sometimes the pharmacist doesn't know, but ... if they tell us it's not a cancer patient, it's more than likely the doc will get investigated. Numbers are certainly an indicator, but they're not the only indicator - it's hard to answer with a straightforward answer. Every case has a different twist to it.

In the absence of a board pain management policy or guideline, decisions about investigating or disciplining a physician were often based on deviations from the recognized standard of care. For example, a respondent from a state that had contemplated but not yet adopted pain management guidelines stated:

[An investigation is triggered by] the deviation from an accepted norm - if someone is prescribing differently from their peers in a specific specialty. As an example, the pain management people will write 10 times the amount of opioids as others. We wouldn't waste time with that person. But if a physician's billing as an internist and prescribing the same as a pain management person, we're going to go find out why. And if the pain management person is prescribing way above others, we'd check that out too. Deviations from a norm we observe, but we don't establish the norm.
Another commented:

[We're] looking at complaints and poor charting, [cases where] the patient "lost the prescription" and the doctor writes another, but there's no documentation of diagnosis or follow-up, etc. The physician's probably gotten on lack of documentation - we can't prove fraud or diversion, but we can prove good medical practice standards were not [maintained].

Several references were made to using judgment in each case:

You have to apply judgment; this is not an area that lends itself to cookbook approaches. You have to react to good intelligence, for example, a reliable source like a pharmacy or another health care provider - their threshold to report to the board is high. We review DEA reports for excess purchases monitored, but pure volume doesn't necessarily indicate a problem. You have to tell whether it's below standard of care, not just volume.

In addition to the volume of opioids prescribed, the credibility of the complaint source, and whether there is documented compliance with the pain management standard of care, board policies or guidelines, or state regulations and statutes, boards look at the egregiousness of the physician's conduct. One instance of highly egregious conduct may be sufficient to warrant a full investigation and subsequent discipline, whereas with milder forms of physician misconduct, a board may look at the number of complaints and evaluate patterns of inappropriate prescribing or practice. The uniqueness of each case was emphasized by many respondents. Comments included: "each case is done on an ad hoc basis; it depends on who is reporting, what the allegations are, how egregious [the physician's conduct was], the past history of the doctor, etc." and "It's not a simple answer; there's no quota system that a specific amount of drug means you're ripe for investigation. We're looking at a number of aggravating factors."

In some states, medical board investigators worked closely with law enforcement, and thus looked closely at the quality of evidence collected against a physician (e.g., witness testimony quality, corroborating evidence - for example, if anyone observed the physician improperly prescribing opioids - hospital records). One respondent stated: "partnership with law enforcement is a very productive way to run an investigation. They're more expert on the criminal side, more able to identify witnesses - like people who get sex for drugs don't want to testify, but police have ways to find willing victims to come forward." 


\section{Discipline for overprescribing}

When asked whether respondents thought the number of physicians in their state who had been disciplined for overprescribing opioids had increased, decreased, or stayed the same in the past 5 years, fifteen ( 39.5 percent) thought the number had stayed the same, fourteen ( 37 percent) thought it had increased, six (16 percent) thought it had decreased, and three had no real impression (see Table 1). Reasons given by those who thought the number had increased included an increase in numbers across the board ("our general numbers have increased" and "everything's gone up; discipline for prescribing violations has not increased more as [a] percentage of the total, we're clearing [backlogged cases] more quickly, we streamlined our processes"); increased awareness ("it has to do with increased public awareness, increased awareness on our part; OxyContin is more realized by all of us," and "there's generally a greater awareness in the professional community and the public about this issue now"); an increased level of sophistication among drug diverters/abusers ("people are more sophisticated about getting drugs"); and increased scrutiny by the medical board ("I think we're more aggressive in taking action because the information is available to the doctors about proper prescribing practices"; "I would think it's ... increased due to increased vigilance. Members of the board are on the lookout for that"; and "the board is paying more attention to these issues, investigating them more seriously, that's my impression").

Reasons given by those who thought the number of physicians disciplined for overprescribing had decreased over the past 5 years involved the redefinition of "overprescribing." Respondents explained: "the board's attitude has changed; now we have pain management guidelines and have an established way of determining if a physician is deviating from those guidelines. We're more aware of the need for adequate pain management and how that should be documented"; "Because the quantity of opioids thought to be appropriate has increased tremendously, those who used to be disciplined now are not considered in violation. The upper limit has been raised, and we're okaying quantities now [that are] four to six times greater than before"; and "I think we were more restrictive than we are now. Now we recognize the necessity for pain management.... [There's] increased vigilance but an acknowledgment that pain management is necessary. We have a policy and pain management guidelines now." Another respondent described a move by the board toward a more proactive approach that averts the need for disciplinary action:

[W] utilize other types of informal processes to try to address a [physician] before a pattern of bad practice is established.... [W] identify [a physician who] ... needs further education but hasn't established the [bad] pattern or egregious conduct
- we move some of those through [a special program that is proactive rather than reactive].

One respondent identified being more proactive with opioid prescribing issues as a goal that his board was moving toward: "I don't think the board has been looked at as being proactive; they've been seen as more reactive, so we're trying to change that. It's hard, though."

Respondents were asked what factors would determine whether their board would discipline a physician for overprescribing opioids. Several respondents commented that each case has a unique combination and presentation of facts, making it difficult to identify specific infractions that would automatically lead to a physician's being disciplined - use of individual judgment was necessary. Comments included: "The board doesn't have any policies or procedures on this. We would look at it on a case-by-case basis"; and "We look for records, tests, documentation, etc., and [the board] make[s] a decision about discipline. Our practices are very subjective." One respondent explained:

We rely on expert testimony. We would consider
the harm to the patient, whether the doctor is board-
certified, how long the doctor's been in practice,
whether there's been any prior discipline, or
whether [there's been] any fraud or financial ex-
ploitation, the severity of the problem, how long
it's been going on, which drugs were used, was a
patient harmed - it wouldn't have to be more
than one patient, though typically it is - and
whether or not the physician was impaired. [If the
latter, the physician would go to rehab and the
board] might not discipline.... The goal is pro-
tecting the public and rehab'ing physicians. You
don't always need discipline to achieve that.

There was generally less subjectivity and inconsistency involved in criminal diversion cases ("[The board is] pretty consistent; we usually get a drug profile, get records, get DEA or police to investigate that, make a criminal arrest or investigate, and get an emergency suspension for 90 days ....").

For many respondents, violation of a medical standard of care was enough to warrant disciplining a physician for opioid overprescribing ("there's no need for a pattern or more than one case. One act or omission failing to meet the guidelines or standard of care is enough if the facts are corroborated," and "the standard really is whether the physician is practicing below the standard of care and whether there's a continued pattern of irregular or substandard care. We usually don't have a problem with showing a pattern, and if the physician is below the standard of care, we're quick to bring action"). Others commented: "we'd discipline based on failure to meet generally acceptable standards 
of practice; usually it's based on poor recordkeeping, [rather than] "overprescribing opioids"; "it's based on adherence to medical standards of practice, and proof of that in documentation."

Respondents mentioned various things they looked for when investigating physicians for violating the standard of care for overprescribing opioids, including poor maintenance of patient records/poor documentation, "upcoding third party billing from a routine to a sick visit when [the visit is] under five minutes - usually you don't even find a blood pressure [charted] - significant findings of another disease entity not being followed, like hypertension or hyperlipidemia, not monitoring or following up," "red flags in the [patient] record like lost meds.... [I]f we see a lot of that stuff, we start to think the doc doesn't know what he's doing. Especially whether the doctor refers out or not [to a pain specialist]," ${ }^{3 \mathrm{~s}}$ "ongoing monitoring, discussion with the patient ... in general, an absence of appropriate documentation to substantiate their professional decision." One respondent reflected on how the pain management standard of care has changed:

What used to be called overprescribing 5 years ago is not that now. There's been a change in the field of pain management. Now we don't discipline for quantity only. The thinking has changed in the practice of medicine. Now we are focusing basically on any practice that could be harmful to the patient, and this is based on standard of practice, which has changed.

However, a few respondents mentioned that standard of care violations would typically not be disciplined by their board, at least not without a demonstrated pattern of infraction by a physician ("we have to see a pattern"; "it would have to rise to negligence on more than one occasion, or inappropriate treatment; we'd have a hearing, there'd be due process, it would have to be a pattern that was established"; and "obviously, any case where we see a pattern of patient harm, willful and repeated violation of prescribing laws and regulations, we'll discipline. But we'll probably try to educate the doc"). One respondent stated:

It depends on all the facts, the pharmacy printout, and we look at the patients - sometimes they doctor shop. But if it looks like the doctor was fully aware that the patient may have an abuse problem and [s] he continued to prescribe, or was asked by the board to take a prescribing course in the past ... if after that the physician is still doing the same kind of thing, we'll step up the disciplinary process.

Boards that had adopted pain guidelines referred to them in making judgments about a particular physician's actions.
One respondent stated: "We look to [our pain rules] to give us guidance as to whether there's a violation. We tend to [apply] formal disciplinary action with doctors who have shown egregious conduct or established a poor pattern of practice." Another commented:

We refer to our pain guidelines. It's not based just on dose but quantity. We realize that people are in pain and need medication for that, but there comes a point where it's not physically possible to consume so many opioids in such a short period of time.

One respondent explained the benefits of referring to a position statement when enforcing opioid prescribing standards for physicians:

We set up the position statement against legal advice, because it doesn't have the same legal standing as a law or rule, but it allows us to articulate the standard of care in each instance. Expert testimony is then used when prosecuting a physician to show that he did not follow the articulated standard. For example, the position statement says you have to see the patient before prescribing drugs for them. This rules out Internet prescribing. We've gone after four docs for prescribing over the Internet without seeing patients first, and we upheld that through the position statement. But the position statement allows us to discriminate [about] when to go after docs. We don't have to go after everybody.... The position statement allows a physician to treat pain, that's standard of care, but it does say that the physician needs to comply with the minimum of appropriate medical practice.

The most common form of sanction imposed in overprescribing cases was mandatory education/retraining. Other sanctions included (listed in order of frequency mentioned): license suspension, license revocation, probation, restriction of opioid prescribing, monitoring of prescribing practices, mentoring and supervision, reprimand/censure, and a fine. One respondent stated:

We classify our drug problems into three categories: failure to follow [standards of medical practice], diverting drugs for self-use, and diverting drugs for money, sex, or other things. We take a very different tack for all three. For the first, we retrain. For the second, we rehab. For the third, we have no patience.

Other comments included: "[the sanction] depends on the severity of the offense, frequency, contrition and recognition 
on the part of the practitioner, whether he's been before the board on an offense"; "I couldn't say, there's such a range everything from revocation to public censure to nothing [to] rehab"; "the sanctions differ depending on the case"; and

I don't always get the sanctions I want. I would like to see temporary suspension of a license and mandatory attendance at an appropriate prescribing workshop. The sanction has to have enough meaning to get their attention. Many can write a $\$ 10,000$ check and they don't miss it.... You've got to take them out of the loop a little while, get their attention big time.

Another respondent explained:

If it's limited to a lack of knowledge, we have a lot of tools to evaluate what to do.... [I]f it's a pretty big problem, we send them to get a report on their skills/knowledge.... [1]f it's a minor knowledge base [problem], we send them to a remediation program.... If there are other quality of care issues, we send them to an evaluation program. Then with doctors trading drugs for sex, that's a character problem; we would invoke longterm [license] suspension or revocation.

\section{Opioid underprescribing: Complaints}

Nineteen respondents ( 50 percent) were aware of complaints to their board against physicians for undertreatment or inadequate treatment of pain in 2001. Based on the thirty-three respondents who were able to estimate the number of complaints, the average per 1,000 doctors in the state was 0.46 (standard deviation $=1.1$, range $=0$ to 5.9$).{ }^{39}$ The major source of such complaints was patients (eight respondents identified nonprisoners as the major source, two identified prisoners, and five reported both prisoners and nonprisoners). ${ }^{40}$ The other primary source of complaints was family members (nine out of nineteen). One respondent explained: "[There are] three major sections that prescribing complaints can fall under: unprofessional conduct, incompetence, and fraud. [Inadequate pain management complaints are] usually in the first two categories." Some felt this problem was underreported ("it's a very underreported problem, in my opinion"; and "I've had orthopods proudly say they've never written for a Schedule II, and my question is 'Why? Aren't you dealing with people with severe pain...?' So I'm sure there's undertreatment, we just don't see the formal complaints."). A few respondents did not perceive undertreatment of pain to warrant a serious response by the board ("[we've received] just a few [complaints about undertreatment of pain]. Normally those were dismissed or no action was taken because the board doesn't perceive that circumstance as a real high threshold of some kind of negligence or incompetence."). Others demonstrated a commitment to the issue, despite the absence of complaints ("as a cancer survivor I'm sensitive to the issue, but I don't see complaints from cancer patients saying the doctor didn't treat my pain carefully" and "I've kind of looked for them, but haven't found any so far.").

A few respondents gave examples of inadequate pain management complaints as being revealed, through investigation, to be instances in which patients were actually receiving adequate doses of opioids or were addicted to opioids and then complaining that they were cut off from their source of drugs. One respondent explained:

We did have one doctor who was overprescribing her patients who were addicted to narcotics, and after we suspended her license, some of them called to complain they couldn't get their meds, but those were [addicts trying to get narcotics, so it's not a legitimate complaint of undertreatment for pain].

Twenty-seven respondents ( 71 percent) thought there had been no change in the number of complaints the board had received in the past 5 years regarding inadequate treatment of pain. Six respondents thought there had been more complaints, and two thought less. Three had no opinion. Those who thought the number of complaints had increased attributed it to increased public awareness ("on a personal level I find [awareness about this issue to have increased] in hospitals; my husband recently had surgery and they were constantly asking him about pain - having him score his pain every time you turned around").

\section{Investigations and discipline for underprescribing}

Respondents were asked to estimate the number of investigations their board had ever conducted related to pain undertreatment. Nineteen respondents thought their board had never investigated a physician for undertreating a patient's pain, and sixteen thought their board had. (Three did not know.) Of the latter sixteen, eleven were able to estimate the number of investigations their board had ever conducted related to undertreatment of pain. The average number of investigations was 1.7 (standard deviation $=3.4$, range $=0$ to 13). Six respondents said all the cases involved nonprisoners, three said they involved only prisoners, and three said both prisoners and nonprisoners. Four did not know. One respondent pointed out that physicians are not required to "treat every patient who comes in the door," so a physician may refuse to refill a new patient's request for opioids - this is different from a physician failing to treat people under his or her care. Only one board had actually disciplined a physician for undertreatment of pain. 
Respondents were given facts from the case regarding Dr. Bilder, the physician who was disciplined by the Oregon Medical Board for undertreating his patients' pain. Seventeen respondents were familiar with the case, ten were not, and eleven were unsure. When asked how likely the respondent's board would be to take disciplinary action against a physician for whom the board had received similar complaints that were later corroborated, eleven respondents thought it was almost a certainty (i.e., greater than 90 percent), fourteen respondents thought it was probable (60-90 percent), three thought it possible (40-60 percent), two thought it unlikely (10-40 percent), and three gave other ranges (between 60-100 percent, and between $40-90$ percent). Five could not say.

Respondents' comments added further insight. Some stated that their board is limited in the kind of disciplinary action it can take ("the law only allows us to take disciplinary action if they're grossly negligent"; "we have to use clear and convincing evidence to prosecute, and that's a pretty high standard of evidence"). Several respondents commented that each case is unique and it would be difficult to predict their board's response ("it depends on the facts" and "the board tries not to make pronouncements on types of cases because they're dependent on facts and circumstances. The doctor may be making the right judgment in that particular situation, it may be appropriate. There are no cookie-cutter answers for these cases."). Some noted that more than one instance of pain undertreatment would be necessary ("you can't establish a pattern of practice with one patient"). Others looked for level of egregiousness ("The decision would be based on the medical record, and if there was a danger to the health, welfare, and safety of the community, that would definitely be a legal basis for [disciplinary action]. If it was found that the situation was egregious, there would be a legal basis for a summary suspension.").

A number of boards appeared disinclined to consider a standard of care violation alone as a basis of disciplinary action in cases of pain undertreatment ("the board tends not to discipline based on standard of care but on [gross] negligence"). One respondent voiced frustration with this general tendency of the respondent's board:

\begin{abstract}
My problem here is we see standard of care [violation] cases all the time, but we don't discipline on [violation of] standard of care. For some reason our reviewer ... says, "well, it's not the best medical care, but it doesn't rise to the level of gross negligence." I wonder, what constitutes gross negligence? ... I don't think we do a good job at all on standard of care. I'd like to think so, but we don't.
\end{abstract}

Some respondents thought that the physician's intent would be relevant ("was he trying to avoid DEA scrutiny rather than intentionally make people suffer?"), implying that a physician's lack of knowledge about adequate pain management would be grounds to evade board sanctions for pain undertreatment ("You would almost have to show criminal cruelty. [Giving Tylenol for cancer pain, knowing it doesn't alleviate the pain,] could show that."). However, a few thought their boards would discipline if they could prove that the standard of care had been violated ("yes, standard of care would be disciplined, depending on the facts"; "we do discipline standard of care issues; it's hard to prove sometimes, but we do"; and "if the physician is just disregarding the patient's complaint [and the patient's] not getting better, standard of care dictates that a follow-up is required and, if [that does] not [happen], then standard of care is not met").

Those whose state medical boards had pain management guidelines or end-of-life legislation used those guidelines, policies, or legislation to benchmark the physician's actions. One respondent stated: "that's just cruel to those patients, and it's not in conjunction with [our] pain management guidelines." Another explained: "our state has pain rules that were made by the board that the physician is expected to follow, and if it was verified that the physician didn't follow them, as would be the case with the physician in this scenario, that physician would most likely be disciplined." Another commented:

A doctor would have to show a pattern of practice of undertreatment, and following our pain guidelines, if the patient's pain was 10 out of 10 and [he's] giving Tylenol or ibuprofen, that's really ridiculous. Our consultants are in pain management and they believe in treating for pain. [But] it's hard to gauge since we've never [disciplined for undertreatment of pain] before. There are eighteen different personalities on our board, and it's hard to say how they'd go.

Yet another respondent stated:

In [this state] you're not held criminally liable for judicious titration in cancer patients, so to get an undertreatment case, you just have to have a real lack of education, and if we saw that, we'd have to utilize some discretion. Why did it happen? Can the physician be educated without sanction and still protect the public?

Several respondents thought that, depending on the facts of the case, a physician would likely be educated about pain management before sterner sanctions were invoked. One respondent stated: “they wouldn't suspend a doctor's license probably, they would probably want re-education. Some of those programs here are very expensive, but the board doesn't let that stop them from recommending such a course." An- 
other explained: "if it was an innocent mistake ... and if there was no pattern ... the remedial board would review another 10-20 charts of that doctor, in a very collegial way, and tell him what he needs to do, and [make it clear that] 'we don't want to see you again.'" One respondent wondered whether sanctioning a physician for undertreating pain would lead to overprescribing problems ("once you discipline someone ... they can go the other way. l've had physicians say, 'Fine, I get disciplined for not doing it, I'll give everybody drugs.”'). One respondent thought, "If you're just coming in and spanking people, [that's not helpful] ... doctors [need] good messages, too.... Our goal isn't just to discipline as much as we can." However, other respondents thought their board was too lenient in dealing with physicians for undertreating pain.

\section{Use of pain management experts}

Respondents were asked whether their board ever used a pain management expert to assist with an investigation involving the prescribing of opioids (either underprescribing or overprescribing). Thirty-one respondents said their board had used such an expert. The mean percentage estimate of cases in which a pain management expert was used was 29.2 percent (standard deviation $=35.0$, range from 0 to 100 percent). ${ }^{41}$ This result must be interpreted cautiously, as some respondents qualified their answer by stating that the denominator of their estimate was investigations involving opioid prescribing for pain management, not opioid prescribing for criminal cases (e.g., physicians illegally prescribing opioids in exchange for sex or money, or self-prescribing). One respondent explained: "we have pain management guidelines that we've published, and it's easy to compare a physician's behavior to those guidelines, but I'd say we refer to a pain management expert in about 20 percent of the investigations, but they [also] use our guidelines." Another stated: "in a case right now we're using a pain management expert, but that's only the second or third time. Usually the cases are pretty clear." Some respondents stated that their boards use a pain management expert whenever disciplining a physician for opioid prescribing practices, or whenever the board has a hearing in which someone testifies against the physician for issues related to opioid prescribing. One respondent explained: "if the nexus of the case is pain management, then a pain management expert is involved." One respondent noted that recent legislation required that a palliative care physician sit on the board. Another stated: "with our budget problems, [we don't use a pain management expert] as often as we'd like ([only] about 20-25 percent [of the time]). [There's] a pretty good mix of physicians on the board and subcommittee. They usually do okay, but sometimes they need the expert."

When asked to name the credentials of the pain management expert used, five respondents mentioned board certification in anesthesiology, twelve mentioned certification in pain management (mostly through anesthesiology pain management certification), seven mentioned experience-based expertise ("usually it's a doctor who's well-respected in the community and works for a pain clinic or runs a pain clinic"), and one mentioned a combination of experience-based and pain-management-credentialed expertise. Six did not know. Several mentioned that they try to match the specialty area of the physician being investigated with that of the consultant ("If it's a family physician, we look for a family physician who also treats chronic pain patients."). One explained: "very few physicians are board-certified in pain management, [but] there are a lot who practice pain management. We would get an internist if an internist was involved, etc." Another reiterated: "few people are certified in pain management, though most [experts] we use, that's their main specialty. They advertise themselves as pain management experts. Most are board-certified in their primary specialty at least. A handful are board-certified in pain management, but not a lot."

\section{Potential chilling effect}

Several respondents commented about the potential chilling effect that could be created by the board's investigations of and disciplinary actions against physicians for opioid prescribing. Some wondered how these fears were propagated. One commented: "the thing that surprises me is that physicians won't prescribe because they say they will get in trouble from the state. Where do they get this idea? ... It's always baffled me where they get that from. Urban myth." Another stated: "there's a perception by many GPs or internists that we are something much bigger than we really are. It's the Big Brother syndrome, like the IRS, a bigger perception than many of us in the regulatory business are really aware of." Others thought there might be some truth to such concerns, as is conveyed in the following comment:

It has gotten out that the board is very active and this has created the feeling of some in the medical community that we're out to get them. And some have asked me if I'm worried that we're being too aggressive, and I do worry about that. But I worry too that they'll forget we're here.

Another responded similarly, emphasizing that the interest in avoiding a chilling effect must be balanced with the board's obligation to protect patients from harm:

Doctors like to cry foul anytime we inquire about anything, and say we've scared them so they're not going to prescribe anything. It's just a problem we have to deal with on a case-by-case basis. There are doctors out there who are harming their patients, and we have to protect the patients too. 


\section{Board-sponsored education/training}

Twenty-eight respondents stated that their board had distributed educational materials regarding treatment of patients with pain. In most cases, these were articles in newsletters or publication of the board's pain management guidelines or rules. Others mentioned distributing press releases, white papers, and pamphlets on the subject. Many of the boards provided the same information on their website. One respondent stated that "our position statement on pain management is given to physicians when they're licensed, and they're interviewed by a board member to reinforce their knowledge of [the position statement]." Others covered appropriate prescribing for pain in mandatory orientation sessions for new physician licensees. In one state, "any new physician who applies has to take a written test based on all the board's rules, [including appropriate opioid prescribing]." Several respondents emphasized that the focus of these educational efforts was on proper documentation and follow-up of patients treated for pain, particularly for chronic pain, e.g., "The [emphasis] that our board has [stressed with] physicians is documenting their treatment plan, diagnosis, and rationale for what [they're] prescribing. That's where physicians will get into trouble. It's necessary for the patient and good for the doctor; for example, if the patient needs to change physicians, those records speak volumes"; and "We sent to physicians [in the state] ... a letter saying basically 'we don't want you to overtreat or undertreat [your] patients' pain, and if you ever have a complaint with us, this is what you need to have in your file, and if you don't have it, you'll probably be in trouble with us." One respondent questioned whether physicians were "getting the message":

[This state] has specific legislation in this practice [chronic pain management] and how it's supposed to be done. We have shared that with physicians in our newsletter, and we give talks, but the word doesn't seem to get out. Physicians who we find are overprescribing complain that "the board's picking on me," but we're not. It's an issue of good medical practice.

Another expressed frustration with the limitations of what could be accomplished by a nonautonomous board:

My board.... can't do a lot of things because [we're] under an umbrella agency that administers our budget and other things. We can complain but are limited in what we can do... such as writing/ distributing educational brochures and all kinds of creative things.... I work with "inside the box" type people, which you see in government agencies a lot. Creativity and innovation are not encouraged, and when you achieve them, you've had to fight hard. Everything is a struggle.
Fourteen respondents reported that their board had provided educational sessions on the treatment of patients with pain. Some were talks and presentations about pain management given at hospitals or other venues. One respondent reported: "[We've] sent staff out to give presentations and have been keeping track of those since 1999. I have a list five pages long of all the places we've gone: 137 presentations since 1998,38 [were] pain management speeches, and 25 [were] overviews with pain management references as part of the content." Another stated: "the executive director has spoken on this.... We try to be as proactive as we can." Others mentioned full- or half-day seminars or training sessions provided by the board on pain management and proper prescribing - some were one-time sessions and others were given annually or more often. One respondent referred to a recently passed law requiring physicians in the state to take " 12 hours of $\mathrm{CME}$ [continuing medical education] on end-of-life care and pain management" as a possible solution to the problem that "a lot of people out there are not being treated appropriately for their pain, and doctors don't recognize that." Another board was "also looking at mandatory CME in pain management for physicians."

Of the twenty-four respondents whose boards did not provide educational sessions on pain management, comments included: "this is being discussed, [but it's] available in the private sector"; "we're talking about providing CME on pain management and end-of-life hospice issues, but ... nothing has been finalized"; "we defer to Purdue and other workshops"; and "I wish we had the staff; however, there are really terrific people putting CME seminars on in the community that are excellent. There's a wealth of resources in this area, so there's no excuse for not having knowledge about pain management."

\section{Balancing the need for appropriate treatment with preventing abuse and diversion}

A few respondents thought that physicians might be hesitant to prescribe opioids to terminally ill patients out of fear that they might hasten the patient's death. One respondent said that the allegations made to the board relating to undertreatment of pain typically involved "a fundamental value system" in which physicians "have very strong feelings about not wanting to hasten a patient's death." In such cases, the board "trie[s] to assure physicians that it's within accepted practice to palliate at the end of life and this is not seen as euthanasia or physician-assisted suicide, but often physicians really struggle with that issue." Most respondents, however, felt that pain management at the end of life had seen the most improvement as far as boards being better able to distinguish adequate opioid prescribing from overprescribing, as is evident in the following comment: 
The board's in a tough spot. As soon as it goes after someone for overprescribing, the first reaction is "that's chilling treatment for pain." They duck for cover under that. But those cases are apples and oranges. Those who are diverting opioids take cash only, they deal with patients who have a criminal history, they don't keep records. There's no comparison to, for example, treating a dying cancer patient. Complete apples and oranges. It's not like someone in hospice, dealing with a patient who needs pain medications. Our board has a position statement on end of life that covers all this.

Some respondents commented on the difficulty in reconciling the changing attitudes and practice standards in pain management of recent years with the ongoing problem of drug abuse and diversion. One stated: "it's a real challenge, finding that balance between under- and overtreating pain." One pointed to the difficulty of managing pain in the fragile elderly: "what might be an appropriate dose for a young person is not for an elderly frail person who's on multiple medications." For some respondents, their job was easier when there was a clearly established upper limit for prescribing opioids, as the following comments demonstrate:

[There's been a] tremendous change in the management of chronic pain and the attitude that there doesn't seem to be any upper limit on opioids. The attitude now is "whatever works." I have problems with that because I'm faced with figuring out whether opioids are being diverted or not, and I have suspicions that a lot of patients are conning a lot of doctors into giving them meds and don't get questioned because of this "whatever works" attitude. We will have to figure out how to counter that.... We used to sanction based on the PDR [Physicians' Desk Reference] limit (like $40 \mathrm{mg}$ a day for oxycodone), but now that's almost never the basis of our sanctions. Patients are on 700 to $800 \mathrm{mg}$ of oxycodone a day.

The numbers we're seeing, the doses are kind of unreal at times. You have a physician who's not educated in pain management, and this might sound bad, but there is this rhetoric about serving chronic pain patients, so physicians tend to do it. Some have good hearts and don't know how to do it well; some don't have the heart but see it as a way to have a practice. But they're not following good medical practice in prescribing, they're just prescribing. They don't have consults, they don't document about what's going on - sometimes it's not even based on good pharmacology, just "oh, this is good." Underprescribing is still an issue, but there's also the issue of people being so overprescribed - we had one woman who was a school bus driver and she couldn't even move [because she was so drowsy from the pain medication].

The following respondent's comment concerns the same issue - how to balance treating valid chronic pain with protection against abuse of opioids:

Chronic pain in my opinion is a subspecialty. Even experts don't agree [on] what to do. The problem I have is not so much with the pain specialists, but at the ... level of general practitioners and internists who end up with patients with chronic pain. Sometimes they do a good job at handling it, sometimes they don't. A lot of these doctors don't know how to say no to patients, they don't really understand what's going on. They can get into trouble if they take everything a patient says at face value. How do you know if I really have a migraine?... It's hard. No doctor really wants to bother with the chronic pain issues. I knew a pain management specialist who said it took 3 months for her to get a feel for whether certain chronic pain patients were lying to get meds. Everyone lies. We've had physicians lie who are under investigation, and if physicians lie, you can bet patients lie.

One respondent agreed that many physicians prefer not to treat patients with chronic pain, and that it is better for them to refer such patients to a pain specialist:

Some chronic pain patients are tough to treat and some doctors feel they don't have the time to spend with those patients. One of the things I always say is don't dabble in pain medicine. Do it right, for the sake of the patient and the doctor. It's better to refer [patients to a pain specialist] than to do it half way.

Yet, another respondent identified the problem of the lack of access to quality chronic pain treatment in pain clinics and centers:

One of the problems is that the pain clinics are undersupported, they're short of doctors willing to practice pain medicine/anesthesiology, they can't get paid. [This causes a] population of people to seek out individual physicians, some of whom lack the skill set to treat this type of patient. It's a difficult problem. One psychiatrist opened a pain clinic, no prescribing experience before. He's gone from none to the top three OxyContin prescribers 
in the state. So, how does that happen? With virtually no records kept. People are walking in with money.

Another agreed:

It's the standard of care to take care of people's pain just like it's the standard of care not to be duped. That shows how colossally difficult the board's job is here. When do you cross over from appropriately treating pain to hurting patients? I think people get into trouble with this because it's easy money for doctors. I think the brass ring is a pain center connected with an academic center, where they're well-trained, well-managed, look at all problems, not just pain. Patients who are marginal and might be abusers are put on contracts and they have ways to keep them from participating in diversional activity.... I'm always impressed with these pain centers ... they make it undesirable for drug-seeking individuals to [use their services.]

Several respondents commented further about the difficulty boards have distinguishing valid chronic pain from drug-seeking behavior. One stated: "With the advent of new end-of-life legislation ... physicians ... feel freer to go ahead and prescribe the pain medications that are needed. This helps a lot, Regarding chronic pain, physicians are much more cautious about that." Another acknowledged:

It's easy if the patient is terminal. It's not so easy with intractable pain. Is this a drug-seeking patient or a patient with valid intractable pain? That's a difficult call for physicians and a difficult call for us. Maybe with time there will be more sophisticated diagnostic tools available to make it easier.

\section{DisCuSSION}

Our study results indicate significant variation among state medical boards regarding experience with and reaction to overprescribing and underprescribing opioids for pain treatment. With respect to overprescribing, states were divided on their perceptions of whether the number of complaints, investigations, and disciplinary actions for opioid overprescribing over the past 5 years had increased, decreased, or stayed the same. The largest group, in each case, indicated they thought the numbers had stayed the same. A slightly smaller, but significant, group thought they had increased, and only a few believed they had decreased. However, it appears from the data that there was consistency in responses regarding trends in complaints, investigations, and disciplin- ary actions. That is, if the number of opioid overprescribing complaints was perceived to have increased in a jurisdiction, the number of investigations and disciplinary actions either increased or stayed the same. Likewise, if the number of complaints stayed the same or decreased, the number of investigations and disciplinary actions either stayed the same or decreased. These results were based on perceptions (rather than actual numbers), as it is still the case that most states lack systems that track complaints based on opioid prescribing.

We questioned whether the presence of a state prescription monitoring program might have had an influence on the number of complaints or investigations related to opioid prescribing. Compared to respondents from states without an electronic prescription monitoring program, we found that respondents from states with such a program were generally more likely to think the numbers of complaints, investigations, and disciplinary actions against physicians related to opioid prescribing had stayed the same over the past 5 years rather than increased or decreased (see Table 2). Regarding estimates of the number of opioid overprescribing and underprescribing complaints received in 2001, there were no statistically significant differences between boards with and boards without an electronic prescription monitoring program. Thus, based on respondents' estimates and perceptions, it does not appear that electronic data tracking mechanisms led to increased numbers of complaints, investigations, or disciplinary actions against physicians related to opioid overprescribing practices.

While nearly two-thirds of respondents reported that opioid overprescribing complaints had decreased or stayed the same, over a third of respondents perceived that opioid overprescribing complaints had increased in their jurisdiction during the past 5 years. This appeared tied to a perception that drug diversion, in general, had been increasing. A significant number of respondents believed that drug diversion on the whole was worse in their state than it was 5 years ago, although some attributed this to more diligent efforts to seek out such diversion. Of the eighteen respondents who thought drug diversion had worsened in their state, fifteen thought that OxyContin had significantly contributed to this problem. On the other hand, of the thirty-three respondents who had an opinion on this issue, fourteen (42 percent) did not think OxyContin was a problem in their state. This is likely due to the variation in abuse patterns of OxyContin across the nation. A large majority of respondents stated that their board had not changed its investigative approach in light of OxyContin concerns, but the overall tone of their comments regarding drug diversion indicated that, in general, their boards had taken more active steps to address this problem.

As regards decisions to investigate physicians for overprescribing, it appears that a number of boards are attempting to find the appropriate balance between identifying physicians who overprescribe and those who are appropriately 


\begin{tabular}{|c|c|c|c|c|c|c|c|c|}
\hline & \multicolumn{2}{|c|}{ INCREASED) } & \multicolumn{2}{|c|}{ DeCreased } & \multicolumn{2}{|c|}{ SuME } & \multicolumn{2}{|c|}{ Don't KNow } \\
\hline & PMP* & no PMP*** & PMP & No PMP & PMP & No PMP & PMP & No PMP \\
\hline $\begin{array}{l}\text { 5-year trend of complaints } \\
\text { for opioid overprescribing }\end{array}$ & $\begin{array}{c}2 \\
(18 \%)\end{array}$ & $\begin{array}{c}12 \\
(44.5 \%)\end{array}$ & $\begin{array}{c}1 \\
(9 \%)\end{array}$ & $\begin{array}{c}3 \\
(11 \%)\end{array}$ & $\begin{array}{c}7 \\
(64 \%)\end{array}$ & $\begin{array}{c}10 \\
(37 \%)\end{array}$ & $\begin{array}{c}1 \\
(9 \%)\end{array}$ & $\begin{array}{c}2 \\
(7.5 \%)\end{array}$ \\
\hline $\begin{array}{l}\text { 5-year trend of complaints } \\
\text { for pain undertreatment }{ }^{\mathrm{B}}\end{array}$ & $\begin{array}{c}1 \\
(9 \%)\end{array}$ & $\begin{array}{c}5 \\
(18.5 \%)\end{array}$ & $\begin{array}{c}1 \\
(9 \%)\end{array}$ & $\begin{array}{c}1 \\
(4 \%)\end{array}$ & $\begin{array}{c}9 \\
(82 \%)\end{array}$ & $\begin{array}{c}18 \\
(66.5 \%)\end{array}$ & 0 & $\begin{array}{c}3 \\
(11 \%)\end{array}$ \\
\hline $\begin{array}{l}\text { 5-year trend of } \\
\text { investigations for opioid } \\
\text { overprescribing }{ }^{\mathrm{C}}\end{array}$ & $\begin{array}{c}5 \\
(45.5 \%)\end{array}$ & $\begin{array}{c}10 \\
(37 \%)\end{array}$ & $\begin{array}{c}1 \\
(9 \%)\end{array}$ & $\begin{array}{c}2 \\
(7.5 \%)\end{array}$ & $\begin{array}{c}4 \\
(36 \%)\end{array}$ & $\begin{array}{c}13 \\
(48 \%)\end{array}$ & $\begin{array}{c}1 \\
(9 \%)\end{array}$ & $\begin{array}{c}2 \\
(7.5 \%)\end{array}$ \\
\hline $\begin{array}{l}\text { 5-year trend of physicians } \\
\text { disciplined for opioid } \\
\text { overprescribing }\end{array}$ & $\begin{array}{c}3 \\
(27 \%)\end{array}$ & $\begin{array}{c}11 \\
(41 \%)\end{array}$ & $\begin{array}{c}1 \\
(9 \%)\end{array}$ & $\begin{array}{c}5 \\
(18.5 \%)\end{array}$ & $\begin{array}{c}6 \\
(56 \%)\end{array}$ & $\begin{array}{c}9 \\
(33 \%)\end{array}$ & $\begin{array}{c}1 \\
(9 \%)\end{array}$ & $\begin{array}{c}2 \\
(7.5 \%)\end{array}$ \\
\hline
\end{tabular}

* "PMP" = state had an electronic prescription monitoring program before $2000(\mathrm{n}=11)$.

** "no PMP" = state did not have an electronic prescription monitoring program before 2000 ( $\mathrm{n}=27$ ).

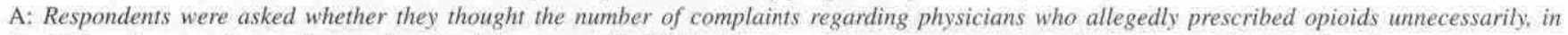
too high a dose, or for too long a duration ("overprescribed") had increased, decreased, or stayed the same over the past 5 years.

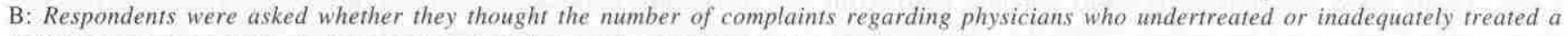
patient's pain had increased, decreased, or stayed the same over the past 5 years.

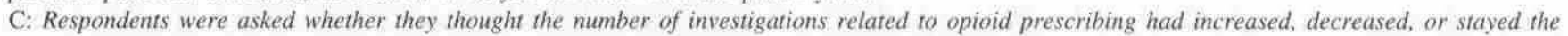

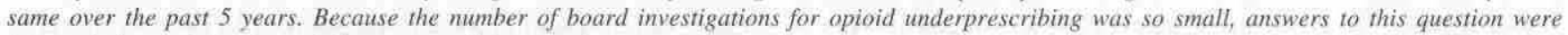
interpreted as relating to opioid overprescribing trends.

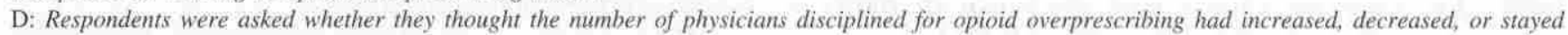
the same over the past 5 years.

treating patients with chronic pain. A number referred to the fact that their board had developed a policy or guidelines for prescribing for chronic pain that were a significant aid to them in deciding whether to investigate or discipline a physician. The number of boards that have adopted pain management guidelines, regulations, or policies has, in fact, increased over the last 4 years, with boards specifically addressing the issue of chronic nonmalignant (or "intractable") pain. In 2001, the PPSG documented a total of eighty-two state pain policies in the form of statutes, regulations, guidelines, or policy statements. As of 2001, twelve states had adopted the FSMB's Model Guidelines in full, and nine in part. ${ }^{42}$

It is unclear to what degree the existence of such policies correlates with a board's commitment to educating physicians about pain management and opioid prescribing issues (i.e., to mitigate the chilling effect that has caused physicians to avoid prescribing opioids when they are needed to treat pain). Although the findings reported here must be interpreted cautiously, it appears that boards with state pain policies that address the treatment of chronic, nonmalignant pain are more proactive, in that these boards provide more pain-management-related education to physicians than boards that do not have such policies (see Table 3). However, we do not know whether the content of such educational efforts strives to balance education about overprescribing with that of pain undertreatment concerns. More research is needed to determine what specific messages boards are sending to physicians in these educational efforts, how physicians are interpreting these messages, and how such educational efforts are affecting physicians' opioid prescribing practices.

Respondents' comments indicate that boards are focusing on making their pain policies known to physicians so that physicians are aware of what is required of them to avoid scrutiny by the board. A number of boards emphasized what should be present in the patient's chart to avoid suspicion by the board that the physician is overprescribing (e.g., patient assessment, pain diagnosis, plan of care, evaluation, follow-up, specialist referral). These efforts serve to reassure physicians that they will not be disciplined for overprescribing opioids to patients with chronic pain if they conform to standards of practice and state pain policies. On the other hand, if a physician is accused of overprescribing and lacks proper documentation of his or her practices, he or she is much more likely to be investigated and disciplined.

An encouraging result for pain management advocates is that boards appear to be moving away from volume or 
quantity of opioids as a primary basis for investigating a physician for overprescribing opioids. Some respondents referred to volume as a trigger but not conclusive evidence for a decision to investigate. Many respondents indicated that these were very fact-specific cases that had to be evaluated individually; that all facts, including the diagnosis of the patient, the documentation of the prescriptions ordered, and consistency with established guidelines, had to be considered. Despite this positive trend away from using volume as a determinative factor in moving forward to investigate or discipline, a few respondent comments were troublesome in that they implied a continued reliance on volume and, in at least one case, a lack of knowledge regarding issues of dosage and volume. For example, the comment, "It's not based just on dose but quantity.... there comes a point where it's not physically possible to consume so many opioids in such a short period of time," might be accurate if referring to an opioid-naïve patient. However, it is possible that a patient with intractable pain might be administered large doses of opioids with a sharp dose escalation (i.e., large doses in a short period of time) in order to obtain pain relief. ${ }^{43}$ Thus, misunderstandings still seem to exist about opioid volume and quantity upper limits (i.e., that the latter exists independently of case-specific facts, which is generally not the case).

In response to the question regarding factors that the board would consider in deciding whether to discipline for overprescribing opioids, most respondents stated that it was a matter of judgment, that it was very fact specific, and often subjective. However, for those that had established pain management policies or guidelines, these appeared key in determining whether to discipline. Significant departures from the policies, in some cases, could be a basis for discipline. Boards varied regarding whether they would require a pattern or more than one instance of overprescribing before disciplining. Poor documentation and recordkeeping were also consistently cited as key factors in disciplining physicians in these cases. A number of boards also mentioned using pain experts to assist them in deciding whether to discipline in cases of overprescribing. A lack of availability of credentialed pain experts may interfere with some boards getting the professional guidance they need to investigate physicians for opioid prescribing practices.

Over half of the respondents (55 percent) thought the number of board disciplinary actions relating to opioid prescribing practices had either stayed the same or decreased over the past 5 years. Respondents who observed a decrease offered reasons that were encouraging for advocates of better pain management. These board representatives thought their board's attitude toward opioid prescribing had changed over the past 5 years and that their pain management guidelines helped them in a number of cases determine that the prescribing practices of the doctor under investigation were

\section{Table 3. Differences in Efforts to Educate Physicians about Pain Management Based on the Existence of a Board Policy Adjressing Chronic, Nonmalignant Pain.}

\section{Pain Management Education TRAINING BX BOARD*}

Pain management content in newsletter Boardos wrth Chronic, Nonmalignant PaIN Policy** $(n=30)$ $54 \%$ (15 of 28 ) $40 \%$

Written pain management materials available/sent to MDs swa. $^{*}$

\section{Pain management content in} orientation

Pain management sessions given by board

\section{BoARDS WTTHOUT CHRONIC, Nonmalignant Pain Policy*** $(n=8)$}

$17 \%$

(1 of 6)

Policies addressing chronic, nonmalignam pain were identified based on the categorization of policies listed on the Pain \& Policy Studies Group website. See Pain \& Policy Studies Group, University of Wisconsin Comprehensive Cancer Center, Data-base of State Laws, Regulations, and Other Official Government Policies, at <http://www.medsch.wisc.edu/painpolicy/matrix.htm> (last updated November 5, 2002).

\footnotetext{
*Respondents were asked: Has your board distributed any educational materials regarding treatment of patients with pain (e.g., copy of guidelines, newslenters, brochures, videos)? Has your board held any educational sessions on treatment of patients with pain? Does the board provide any additional assistance to physicians seeking guidance for the treatment of patients with pain? If respondents answered affirmatively, they were asked to describe the types of materials, sessions, or additional assistance. Information here is based on a content analysis of respondents comments. Percentages are valid totals. Missing data are the result of respondents who completed a written survey, answered "yes" to any of the questions, but did not provide qualitative elaboration.

**These are statutes, regulations, guidelines, or policies that address treatment of or opioid prescribing for chronic, nonmalignant pain.

*:*kThese included pain-management-related brochures, copies of pain policies, position statements, and the like that were available upon request and/or distributed to physicians (e.g., by mail or other methods of distribution).
} 
reasonable, where prior to the adoption of the guidelines they might have disciplined the physician.

The number of estimated complaints boards received for underprescribing were significantly fewer than those received for overprescribing (in 2001, an average of 0.46 versus 3.13 complaints, respectively, per 1,000 doctors in the state). A significant majority saw no change in the number of complaints received for underprescribing over the past 5 years. While some respondents thought the problem of pain undertreatment was real and merely underreported, others did not seem to view undertreating pain (particularly chronic, nonmalignant pain) as a significant problem.

While not equivalent to complaints received for overprescribing, it appears that the number of complaints for underprescribing has increased. Martino conducted interviews with medical board executives between November 1997 and January $1998 .{ }^{44}$ At that time, only one board (California) of the thirty-six surveyed had received a complaint or report explicitly alleging undertreatment of chronic pain. Several had received complaints from prison inmates alleging that certain medications had been denied as a form of punishment, but they generally were not pursued as pain undertreatment cases.

As regards disciplinary action for undertreating, many boards appear disinclined to discipline simply for violation of standard of care, which is how many respondents depicted cases of underprescribing pain medication. They would be more likely to recommend education to the physicians in such cases. This appeared somewhat at odds with the responses given to questions about disciplining for overprescribing, where respondents said they were more likely to discipline for violation of standard of care, even without a pattern of poor practice. Thus, there is a lack of parity in application of standard of care and patient harm as bases for discipline in cases of undertreatment versus overtreatment. Overprescribing is more often seen as a clear violation of standard of care and a clear example of patient harm, while many respondents, or their boards, do not view undertreatment, particularly for chronic pain, in the same way. They appear to apply a higher threshold of harm for undertreating pain.

A number of respondents, however, did provide examples of cases they thought could be construed as gross negligence or egregious behavior regarding pain undertreatment and said that such cases might lead to disciplinary action. Consistent with this response, a significant majority of respondents (79 percent) said that if they were presented with a case where the facts were similar to those of Dr. Bilder (the physician who was disciplined for underprescribing by the Oregon Medical Board), it was either highly likely or probable that they would discipline the physician.

In regard to the potential chilling effect of the board's efforts to oversee opioid prescribing practices, some respondents showed concern that physicians might "go the other way" (i.e., overprescribe opioids if disciplined for undertreating pain, and vice versa). Some boards were working diligently to ease physicians' fears that they would be investigated or disciplined by the board for prescribing opioids to patients. Several thought such fears were completely unfounded or perhaps a convenient excuse to avoid the added work involved in treating chronic pain patients. Others realized that the board's actions had a chilling potential, but thought there was little they could do, that it was the physician's fault for jumping to false conclusions, and that such is the price that is paid for protecting patients. These respondents were aware of the problem of inadequate pain management, but seemed to give more weight to concerns about overprescribing. Respondents spoke of "protecting patients from harm," yet did not view opioid overprescribing and pain undertreatment equally in the degree of public protection they demanded. This type of attitude may contribute to a shortage of physicians who are able and willing to treat patients who have chronic pain. While advocacy for pain management on the part of many state boards may ease physicians' fears about being disciplined for opioid overprescribing, many physicians may decide that their safest (or least burdensome) course is to refer patients with chronic pain to a pain specialist. With the number of patients suffering from chronic pain greatly outnumbering the number of qualified pain specialists, the results do not add up in favor of those with chronic pain.

\section{CONCLUSION}

In sum, we cautiously conclude from our survey results that the attitudes and practices of medical boards toward physicians' prescribing of opioids have changed for the better over the last several years. Respondents' references to the need for "balance" between ensuring appropriate treatment of pain and disciplining physicians who are inappropriately prescribing opioids are illustrative of this movement. The work of a number of individuals and agencies, including the Wiscon$\sin$ Pain \& Policy Studies Group, the American Society of Law, Medicine \& Ethics, the Federation of State Medical Boards, through its Model Guidelines, and the recent DEA joint statement, has reinforced this message of the need for balance and may have played a role in moving boards forward on this learning curve. Moreover, boards' abandonment of opioid quantity as a marker of questionable practice, in favor of an individual assessment of whether the physician has appropriately evaluated the patient, prescribed consistent with board guidelines, and appropriately documented his or her prescribing, further indicates progress in board recognition of the need for adequate pain treatment.

At the same time, some attitudes and practices by boards remain problematic - in particular, a continued tolerance of undertreatment. While many boards are becoming more proactive in educating physicians about pain management 
issues, the focus is on what physicians who prescribe opioids for pain must do to avoid board scrutiny. There appears to be a discrepancy in the weight given to violation of standard of care, patient harm, and gross negligence for overprescribing as compared to underprescribing. Ironically, boards seem to have a higher threshold for patient harm in cases involving pain undertreatment - particularly for chronic, nonmalignant pain. To this extent, physicians may be getting mixed messages from boards: on the one hand, that effectively managing their patients' pain is the expected standard of care; and on the other hand, that the board is more concerned about opioid overprescribing than underprescribing. Perhaps this is unavoidable given the realities of opioid diversion practices. In terms of lessons one might take away from these findings, reformers may have to accept that management of chronic pain inevitably carries with it a greater chance of entanglement with licensing and law enforcement authorities than management of cancer pain, given the higher risks of diversion.

\section{ACKNOWLEDGMENTS}

Funding for this study was provided by the Mayday Foundation. The authors would like to acknowledge Aaron Gilson of the Pain \& Policy Studies Group at the University of Wisconsin, Sandra Johnson at Saint Louis University School of Law, and Jack Schwartz and Tom Keech at the Maryland State Attorney General's Office, for their helpful input into the design of the survey tool used in this study and/or feedback on earlier versions of this manuscript.

\section{REFERENCES}

1. D.E. Hoffmann, "Undertreating Pain in Women: A Risky Practice," Journal of Gender-Specific Medicine, 5 (2002): 10-15, at 12 .

\section{Id. at 12}

3. Id., citing A.M. Martino, "In Search of a New Ethic for Treating Patients with Chronic Pain: What Can Medical Boards Do?," Journal of Law, Medicine \& Ethics, 26, no. 4 (1998): 33249 , at 332 .

4. D.A. Marcus, "Treatment of Nonmalignant Chronic Pain," American Family Physician, 61 (2000): 1331-38, 134546; R.K. Portenoy, "Opioid Therapy for Chronic Nonmalignant Pain: Clinician's Perspective," Journal of Law, Medicine \& Ethics, 24, no. 4 (1996): 296-309.

5. A.G. Lipman, "Treatment of Chronic Pain in Osteoarthritis: Do Opioids Have a Clinical Role?," Current Rheumatology Reports, 3 (2001): 513-19.; B.H. McCarberg and R.L. Barkin, "Long-Acting Opioids for Chronic Pain: Pharmacotherapeutic Opportunities to Enhance Compliance, Quality of Life, and Analgesia," American Journal of Therapy, 8 (2001): 181-86.

6. G.M. Aronoff, "Opioids in Chronic Pain Management: Is There a Significant Risk of Addiction?," Current Review of Pain, 4 (2000): 112-21; K.L. Sees and H.W. Clark, "Opioid Use in the Treatment of Chronic Pain: Assessment of Addiction," Journal of Pain \& Symptom Management, 8 (1993): 257-64.

7. M. Massing, The Fix (New York: Simon \& Schuster, 1998).
8. S.H. Johnson, "Disciplinary Actions and Pain Relief: Analysis of the Pain Relief Act," Journal of Law, Medicine E Ethics, 24, no. 4 (1996): 319-27.

9. C.S. Hill, Jr., "TBS/TCPI Pain Symposium in Conjunction with TexMed 2002," Texas Pain Bulletin (July 2002): at description of presentation by Frank Adams, M.D., at the Texas Pain Society and the Texas Cancer Pain Initiative's Symposium, Opioids, Medicine and the Law, Dallas, April 19, 2002, available at $<$ http://www.texaspain.org/displaycommon. $\mathrm{cfm}$ ?an =1\&sub articlenbr $=5>$; Hoover v. Agency for Health Care Administration, 676 So. 2d 1380 (Fla. Dist. Ct. App. 1996); In re DiLeo, 661 So. 2d 162 (La. Ct. App. 1995).

10. C.S. Hill, "The Barriers to Adequate Pain Management with Opioid Analgesics," Seminars in Oncology, 20 (1993): 1-5; M.L. Levin et al., "Management of Pain in Terminally III Patients: Physician Reports of Knowledge, Attitudes, and Behavior," Journal of Pain o Symptom Management, 15 (1998): 27-40.

11. D.Y. Brockopp et al., "Barriers to Change: A Pain Management Project," International Joumal of Nursing Studies, 35 (1998): 226-32. Research has shown the fears of addiction and overdose or hastened death with opioid use to be highly exaggerated. See M. Bercovitch et al. "High Dose Morphine Use in the Hospice Setting. A Database Survey of Patient Characteristics and Effect on Life Expectancy," Cancer, 86 (1999): 871-77; K.J. Boyd and M. Kelly, "Oral Morphine as Symptomatic Treatment of Dyspnoea in Patients with Advanced Cancer," Palliative Medicine, 11 (1997): 277-81.

12. See Johnson, supra note 8.

13. A. Alpers, "Criminal Act or Palliative Care? Prosecutions Involving the Care of the Dying," Journal of Law, Medicine o Ethics, 26, no. 4 (1998): 308-31.

14. J.H. Von Roenn et al., "Physician Attitudes and Practice in Cancer Pain Management. A Survey from the Eastern Cooperative Oncology Group," Annals of Internal Medicine, 119 (1993): 121-26.

15. D.C. Turk et al., "Physicians' Attitudes and Practices Regarding the Long-Term Prescribing of Opioids for Non-Cancer Pain," Pain, 59 (1994): 201-08.

16. D.E. Weissman et al., "Wisconsin Physicians' Knowledge and Attitudes About Opioid Analgesic Regulations," Wisconsin Medical Journal, 90 (1991): 671-75.

17. See Turk et al., supra note 15.

18. D.E. Joranson et al., "Pain Management, Controlled Substances, and State Medical Board Policy: A Decade of Change," Journal of Pain \& Symptom Management, 23 (2002): 138-47, at 140. 19. Id.

20. The Mayday Fund was established in 1992 with funds from the estate of the late Shirley Steinman Katzenbach. It is dedicated to the reduction of the physical and psychological effects of pain. See <http://www.painandhealth.org/mayday/ mayday-home.html $>$.

21. FSMB's Model Guidelines were adopted on May 2, 1998. They recommend evaluation of the pain patient by the physician, formulation of a treatment plan, securing informed consent for treatment, performing periodic review of therapy and outcomes, obtaining appropriate consultations or referrals for patients when necessary (e.g., patients with substance abuse history), keeping accurate and complete medical records, and maintaining compliance with controlled substance laws and regulations. See S.H. Johnson, "Introduction: Legal and Regulatory Issues in Pain Management." Journal of Law, Medicine o Ethics, 26, no. 4 (1998): 265-66.

22. D.E. Joranson et al., 2001 Annual Review of State Pain Policies: A Question of Balance (Madison: Pain \& Policy Studies Group, University of Wisconsin Comprehensive Cancer Center, 
2002), available at < www.medsch.wisc.edu/painpolicy/publicat/ 01 annrev/contents.htm>.

23. E. Goodman, "From Oregon, A Call for Compassionate Care," Boston Globe, September 9, 1999.

24. "Promoting Pain Relief and Preventing Abuse of Pain Medications: A Critical Balancing Act," a Joint Statement from 21 Health Organizations and the Drug Enforcement Administration (October 21, 2001), available at <http://www.medsch. wisc.edu/painpolicy/dea01.htm $>$.

25. See U.S. Drug Enforcement Administration, OxyContin: Pharmaceutical Diversion, Drug Intelligence Brief (March 2002), available at <http://www.usdoj.gov/dea/pubs/intel/02017/ 02017.html>.

26. B. Meier, "OxyContin Prescribers Face Charges in Fatal Overdoses," New York Times, January 19 2002; B. Meier, "A Small Town Clinic Looms Large as a Top Source of Disputed Painkillers," New York Times, February 10, 2001.

27. Individuals who reviewed the draft survey include: Aaron Gilson from the Pain \& Policy Studies Group at the University of Wisconsin, Sandra Johnson from Saint Louis University School of Law, Jack Schwartz and Tom Keech from the Maryland State Attorney General's Office, Kathryn Tucker from Compassion in Dying, and Irwin Weiner, a retired physician board member of the Maryland Board of Physician Quality Assurance.

28. The survey was designed to be administered during a phone interview, but a minority of respondents opted to complete the survey in written form.

29. See Pain \& Policy Studies Group, University of Wisconsin Comprehensive Cancer Center, Data-base of State Laws, Regulations, and Other Official Government Policies, at <http:// www.medsch.wisc.edu/painpolicy/matrix.htm $>$ (last updated November 5, 2002).

30. See Pain \& Policy Studies Group, University of Wisconsin Comprehensive Cancer Center, Prescription Monitoring Programs, at < http://www.medsch.wisc.edu/painpolicy/domestic/ diversion.htm> (last visited February 12, 2003).

31. In addition to formal written complaints, twenty-two of the thirty-eight respondents also accepted complaints by phone, e-mail, or anonymously, although anonymous complaints were investigated only in rare circumstances (i.e., regarding serious complaints when sufficient information was provided to investigate further). Some states first considered allegations that were transformed into complaints after a formal process in which preliminary evidence was collected.

32. This could include complaints against physicians for prescribing opioids for pain patients they were treating, prescribing for themselves, or trading opioids for money or sex.

33. This is consistent with the findings of Weiner and Pound in their "Project on Legal Constraints on Access to Effective Pain Relief," in which they interviewed medical board members (cited in Johnson, supra note 8, at 321), and found that the boards were "not able to separate actions against physicians treating patients for pain from the more general disciplinary category of abuse of prescription drugs."

34. The actual range of values was 0 to 250 . To correct for the outlier values of 100 and 250 , these values were "windsorized" to the next highest values of 57 and 58 , respectively. Those numbers were then divided by the number of physicians per state (see data at < http://www.education-world.com/a_lesson/ TM/WS_census_states.shtml >) and multiplied by 1,000 .
35. The task of investigating and disciplining physicians was implemented by different individuals, departments, or agencies, depending on the structure of the board and whether it was part of an "umbrella" agency. When referring to boards' investigating or disciplining physicians, we are referring to whatever mechanism the individual board implements to investigate or discipline physicians in that particular state.

36. See Pain \& Policy Studies Group, supra note 29.

37. The lowest dose of OxyContin is $10 \mathrm{mg}$. An opioid-naïve patient with chronic pain is typically started on $10 \mathrm{mg}$ of OxyContin twice a day, and the dose is increased until the patient's pain is controlled (unless the pain is refractory to opioid therapy or other circumstances exist). Suggested dosing for OxyContin is twice a day or every 12 hours, not four times a day. Patients with cancer pain are more likely than patients with chronic nonmalignant pain to take larger daily doses, but there is usually no way of knowing by daily $\mathrm{mg}$ dosing alone whether a physician has overprescribed OxyContin for an individual patient.

38. The respondent conveyed that referral to a pain management specialist would be expected for primary care physicians treating patients with complex chronic pain.

39. Eighteen respondents thought their boards had not received any such complaints - their pain undertreatment complaint estimate was entered as zero. Of the nineteen who thought their boards had received such complaints, fifteen were able to give a 2001 estimate. If a range was given, the median of the range was entered. The actual range of values was 0 to 25 . To correct for the outlier value of 25 , that value was "windsorized" to the next highest value of 13 . Raw values were then divided by the number of physicians per state (see data at <http:// www.education-world.com/a lesson/TM/WS_census_states. shtml $>$ ) and multiplied by 1,000 .

40. We specifically asked about prisoners as a source of complaints, as they tend to file complaints with state medical boards regarding poor medical care in general. One respondent said he "tended to investigate most prisoner complaints because they're in a duress situation; they might not get the best care," while another commented, "Some department of corrections issues, like prisoners' being undertreated, we don't investigate. Even if it's true, are we going to do anything about it?"

41. Estimates for four of the five respondents whose boards had not used a pain management expert were entered as zero (one reported no cases of pain undertreatment complaints and did not know the number of opioid overprescribing complaints. We did not assume that this board had complaints about opioid prescribing to investigate, so we considered data for that board as missing). Of the twenty-three respondents whose boards had used a pain management expert and who gave an estimate of the percentage of investigations in which such an expert was used, if a range was given, the median of the range was entered.

42. Joranson et al., supra note 22.

43. The following scenarios may also indicate inappropriate quantities of opioids being prescribed: (1) the doctor is prescribing relatively low dose tablets but in great volume and does not know to shift the patient to a higher dose, a longer acting version, or a different drug, when the current drug is no longer effective; (2) the doctor may be prescribing in the hundreds of tabs a day. However, focusing on quantity alone is generally insufficient to determine that a physician is overprescribing.

44. See Martino, supra note 3. 
Copyright $@ 2003$ EBSCO Publishing 